\title{
Over-expression of AtPAP2 in Camelina sativa leads to faster plant growth and higher seed yield
}

\author{
Youjun Zhang ${ }^{1}$, Laura Yu², Ka-Fu Yung ${ }^{3}$, Dennis YC Leung ${ }^{2}$, Feng Sun ${ }^{1}$ and Boon L Lim*
}

\begin{abstract}
Background: Lipids extracted from seeds of Camelina sativa have been successfully used as a reliable source of aviation biofuels. This biofuel is environmentally friendly because the drought resistance, frost tolerance and low fertilizer requirement of Camelina sativa allow it to grow on marginal lands. Improving the species growth and seed yield by genetic engineering is therefore a target for the biofuels industry. In Arabidopsis, overexpression of purple acid phosphatase 2 encoded by Arabidopsis (AtPAP2) promotes plant growth by modulating carbon metabolism. Overexpression lines bolt earlier and produce 50\% more seeds per plant than wild type. In this study, we explored the effects of overexpressing AtPAP2 in Camelina sativa.

Results: Under controlled environmental conditions, overexpression of AtPAP2 in Camelina sativa resulted in longer hypocotyls, earlier flowering, faster growth rate, higher photosynthetic rate and stomatal conductance, increased seed yield and seed size in comparison with the wild-type line and null-lines. Similar to transgenic Arabidopsis, activity of sucrose phosphate synthase in leaves of transgenic Camelina was also significantly upregulated. Sucrose produced in photosynthetic tissues supplies the building blocks for cellulose, starch and lipids for growth and fuel for anabolic metabolism. Changes in carbon flow and sink/source activities in transgenic lines may affect floral, architectural, and reproductive traits of plants.

Conclusions: Lipids extracted from the seeds of Camelina sativa have been used as a major constituent of aviation biofuels. The improved growth rate and seed yield of transgenic Camelina under controlled environmental conditions have the potential to boost oil yield on an area basis in field conditions and thus make Camelina-based biofuels more environmentally friendly and economically attractive.
\end{abstract}

Keywords: AtPAP2, Camelina sativa, Fatty acid, Photosynthesis, SPS, Sucrose

\section{Background}

Crop plants obtain energy entirely by photosynthesis; this autotrophic mechanism has long been a target of research aiming to maximize crop production [1]. Sugars derived from photosynthesis are energy sources for metabolism and are building blocks of complex carbohydrates [2]. Sugars also regulate expression of photosynthetic genes in mesophyll and interact with other signaling pathways involved in plant growth regulation [3]. Previous studies suggest that photosynthetic performance

\footnotetext{
* Correspondence: bllim@hku.hk

'School of Biological Sciences, the University of Hong Kong, Pokfulam, Hong Kong, China

Full list of author information is available at the end of the article
}

can be improved by modifying sugar-signaling mechanisms [3]. A large number of protein kinases, protein phosphatases and transcription factors are involved in these pathways [4]. Constitutive expression of Arabidopsis purple acid phosphatase 2 (AtPAP2) by the CaMV35s promoter in Arabidopsis enhances plant growth and seed yield by modulating carbon metabolism [5]. Both sucrose phosphate synthase (SPS) activity and sucrose content are elevated in leaves of transgenic lines. Overexpressed lines grow faster and produce $>50 \%$ more seeds per plant than wild type [5]. AtPAP2 is targeted to both chloroplasts and mitochondria by its C-terminal hydrophobic motif; removal of this motif eliminates growthpromoting phenotypes, indicating that its subcellular
C Biomed Central

(C) 2012 Zhang et al; licensee BioMed Central Ltd. This is an Open Access article distributed under the terms of the Creative Commons Attribution License (http://creativecommons.org/licenses/by/2.0), which permits unrestricted use, distribution, and reproduction in any medium, provided the original work is properly cited. 
localization within the two key energy-generating organelles in plants is important for its biological functions [5]. Purple acid phosphatases (PAPs) constitute a family of acidic binuclear metalloenzymes that hydrolyse phosphate esters and anhydrides under acidic conditions [6]. Plant PAPs are generally considered to mediate phosphorus acquisition and redistribution through their ability to hydrolyze phosphorus compounds $[7,8]$. Some PAPs have biological functions other than those involved in P metabolism. For example, certain PAPs, such as GmPAP3 [9] and AtPAP17 [10], have peroxidase activity. The tobacco purple acid phosphatase NtPAP12 dephosphorylates phosphoryl residues of apoplasticproteins [11]. The enzyme is actively transcribed in the process of cell wall regeneration [12]. AtPAP2 is currently the only PAP known to be involved in carbon metabolism.

Arabidopsis thaliana and Camelina sativa are members of the Angiosperm Family Brassicaceae [13]. Camelina sativa, or false flax, has been cultivated for oil in Europe, Central Asia and North America. Compared with rapeseed, the cultivation of Camelina has become vanishingly small since World War II [14]. Currently, Camelina is being grown to produce aviation biofuels. To date, Japan Airline, Air New Zealand and the US Navy (F/A18) have successfully completed test flights with a 50/50 blend of Camelina-based biofuel and petroleum-based jet fuel. With its low requirements for water and fertilizers, Camelina could be grown on marginal land as a low-input biofuel crop [15]. With an oil content of $>40 \%$ polyunsaturated fatty acids (linoleic acid, 18:2n6 and $\alpha$-linolenic acid, 18:3n-3), of which, linolenic acid makes up $\sim 35 \%$, Camelina seed is also an important source of omega-3 fatty acids [16].

Through overexpression of AtPAP2, transgenic Camelina lines grow faster and produce more seeds than wild-type (WT) plants under controlled environmental conditions. These phenotypes are attributable to elevated photosynthetic rates and SPS activity in leaves. Higher seed yield would make cultivation of Camelina more economical and environmentally-friendly. High seed yield per unit area would enhance biofuel production and reduce consumption of fossil fuels, thus reducing $\mathrm{CO}_{2}$, methane $\left(\mathrm{CH}_{4}\right)$ and nitrous oxide $\left(\mathrm{N}_{2} \mathrm{O}\right)$ emissions.

\section{Results}

AtPAP2 overexpression accelerated Camelina growth

Multiple independent overexpression lines of Camelina sativa with AtPAP2 protein expression were obtained through Agrobacterium transformation. After confirmation by genomic PCR and western blotting (Figure 1), three independent T2 AtPAP2 overexpression (OE) lines were selected for characterization. When there was a 3:1 segregation of $\mathrm{T}_{1}$ transgenic seeds, null-lines were selected for their relatively short hypocotyl lengths on MS plates. Identities of the three null-lines were confirmed by

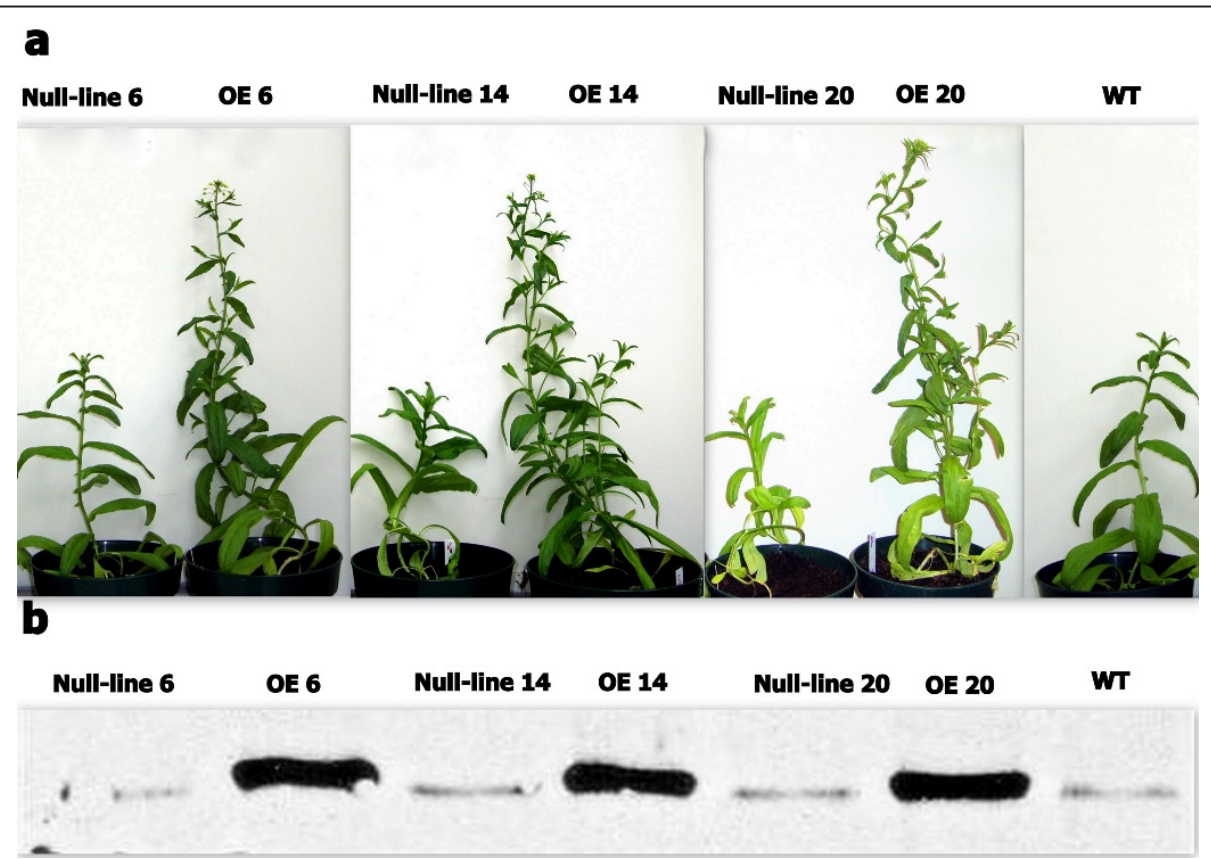

Figure 1 Growth phenotype of transgenic Camelina at day 40. a, All three OE lines produced more branches, grew faster, and flowered earlier than the WT and null-lines. b, Expression of AtPAP2 in OE lines was confirmed by Western blotting using AtPAP2-specific antibodies. OE lines had higher expression of AtPAP2, while there was a homologous protein of AtPAP2 in Camelina. 
genomic PCR and western blotting (Figure 1). A weak western blot signal was observed in protein extracts from the null lines and WT. We attribute this signal to likely cross-reactivity between the AtPAP2 antibody and the endogenous AtPAP2-like protein (91\% amino acid sequence identity) that has been detected in transcriptome analysis of Camelina sativa leaves (unpublished data). All plants were grown on MS agar for a week and then transferred to a growth chamber $\left(150 \mu \mathrm{mol}\right.$ photons $\left./ \mathrm{m}^{2} / \mathrm{s}\right)$ under a $16 \mathrm{~h}$ light $22^{\circ} \mathrm{C} / 8 \mathrm{~h}$ dark $18^{\circ} \mathrm{C}$ photoperiod/temperature regimen. The plants were transferred immediately after first flowering to greenhouse conditions at $22^{\circ} \mathrm{C}$ under Hong Kong's natural day/night photoperiod. Compared to WT and their respective null-lines, all three AtPAP2 overexpressor lines (OE6, OE14 and OE20) grew faster and produced more lateral branches (Figure 1). Typically, plants of the three OE lines started flowering 79 days earlier than WT and null-lines in all three generations. Only the results of the T3 generation are presented in Table 1 for statistical reason. When the WT and three null-lines first flowered at an age of 40-d, AtPAP2 OE lines had already produced more branches (Figure 1).

\section{Longer hypocotyls in OE lines}

Homologous seeds of three OE lines, three null-lines and the WT were germinated on MS plates and the lengths of hypocotyls and roots were measured 5 days after germination. The three OE lines had longer hypocotyls than their respective null-lines and WT, but there was no significant variation in lengths of roots among lines (Figure 2). The longer hypocotyls may have resulted from the larger seed size in overexpressor lines (Figure 3).

\section{OE lines produced larger seeds and had higher seed yields}

Seeds were collected from all lines after full maturity. Seed weights and sizes were measured after drying. The transgenic lines produced larger seeds (Figure 3a-g) and the hundred-seed-weights from OE plants were 50 $110 \%$ higher than those of WT and null-lines (Figure 3h), which may be attributable to an elevated supply of photoassimilates in OE plants. Larger seeds may provide more carbon for seed germination and seedling growth, with correspondingly longer hypocotyls (Figure 2). Generally, total seed yield of OE lines was significantly higher than WT or null-line yields (Table 2), which we attribute to the higher photosynthetic rate in the overexpressors (Table 3). There was no significant difference in germination rates among WT, null-lines and the OE lines (data not shown).

\section{Higher photosynthetic rates and stomatal conductances in OE lines}

Photosynthetic activity and stomatal conductances were measured with a Licor LI-6400XT Portable Photosynthesis System. Third mature leaves below the shoot tips of all plants (35-37-d old) grown in the growth chamber were used for measurements. The OE lines had higher rates of photosynthesis than WT plants and null-lines at photon flux densities over $200 \mu \mathrm{mol} \mathrm{m} \mathrm{s}^{-2}$ (Table 3). In general, photosynthetic activities per unit leaf area were elevated by $10-25 \%$ in overexpressors. As the OE lines had both more branches (and thus greater leaf areas) and higher photosynthetic rates per unit leaf area, each of the $\mathrm{OE}$ plants was able to fix more $\mathrm{CO}_{2}$ than plants of other lines. In photosynthetic leaves, stomatal conductance is coordinated with $\mathrm{CO}_{2}$ requirements of the mesophyll [17]. In our test system, transgenic plants had greater stomatal conductances than WT and null-line plants, in congruence with the elevated photosynthetic rates of overexpressors (Table 4).

\section{Lower sucrose content in leaves of OE lines}

Sugars and sugar-derived metabolic signals affect source-sink balances and carbon partitioning in plants $[3,18]$. Sugars trigger global repression of photosynthetic gene transcription in plants [4]. To determine whether there were changes in sugar level, we used HPLC methodology to analyze sugar content in leaves of 35-day old Camelina. While hexose contents of three AtPAP2 overexpressors were not significantly different from those of the WT and three null-lines, the sucrose contents in leaves of all three transgenic lines were $20 \sim 30 \%$ lower in the transgenic plants (Table 5). The low levels of sucrose in leaves may have enhanced photosynthesis, growth rate and biomass accretion [19].

\section{Increased SPS activity in OE lines}

Sucrose phosphate synthase (SPS) is a key enzyme in the sucrose synthesis pathway; it catalyzes conversion of frucose-6-phosphate (Fru6P) and UDP-Glucose (UDPG) to sucrose-6-phosphate [20]. Overexpresssion of SPS in Arabidopsis [21] and tobacco [22] affects leaf carbohydrate contents and whole plant development. The

Table 1 Flowering time of T3 Camelina

\begin{tabular}{llllllll}
\hline & OE6 & OE14 & OE20 & Null-line 6 & Null-line 14 & Null-line 20 & WT \\
\hline Days to flowering & $43 \pm 2^{\mathrm{a}}$ & $43 \pm 2^{\mathrm{a}}$ & $43 \pm 2^{\mathrm{a}}$ & $54 \pm 2^{\mathrm{b}}$ & $54 \pm 2^{\mathrm{b}}$ & $54 \pm 2^{\mathrm{b}}$ & $51 \pm 3^{\mathrm{b}}$ \\
\hline
\end{tabular}

Plants were raised in a growth chamber under a $16 \mathrm{~h}$ light $22^{\circ} \mathrm{C} / 8 \mathrm{~h}$ dark $18^{\circ} \mathrm{C}$ photoperiod/temperature regimen, and then transferred to a greenhouse after flowering. The results were confirmed in 3 independent experiments. Values are means \pm SD $(n=4-6)$. Different lower case letters indicate significantly different $(p<0.05)$ 

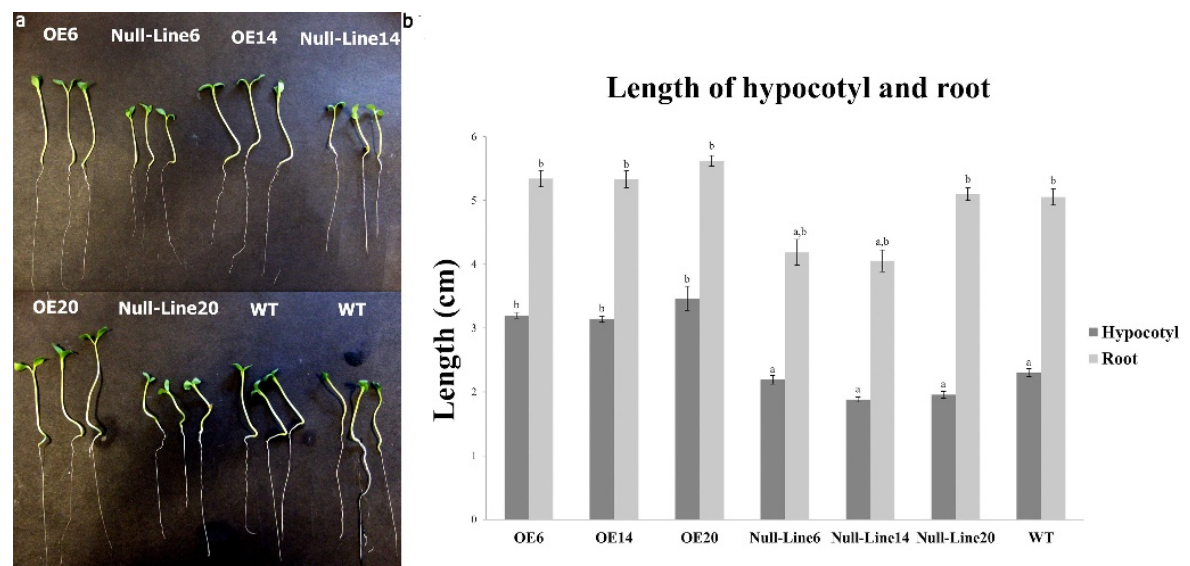

Figure 2 Five-day old transgenic seedlings grew longer hypocotyls. a, Three OE lines grew longer hypocotyls than WT and null-line plants. $b$, Lengths of hypocotyls and roots. Transgenic lines had longer hypocotyls, but there was no significant variation in root length among lines. Values are means $\pm S D(n=9-14)$. Different lower case letters indicate significantly different means $(p<0.05)$.

phenotypes of Camelina AtPAP2 OE lines may be attributable to enhanced enzyme activity during sucrose synthesis. SPS activity was elevated in leaves of AtPAP2 OE plants at both optimal $\mathrm{V}_{\max }$ and limiting $\mathrm{V}_{\text {limit }}$ capacities (Table 6). Higher photosynthetic rates (Table 3) and SPS activity in OE lines may have supplied more sucrose for growth.

Unaltered protein expressions of FBP aldolase SnRK1.1 (and its phosphorylation status), nitrate Reductase, and FBPase in OE lines

SnRK1 protein kinase in plants balances cellular energy levels by regulating ATP production and consumption;

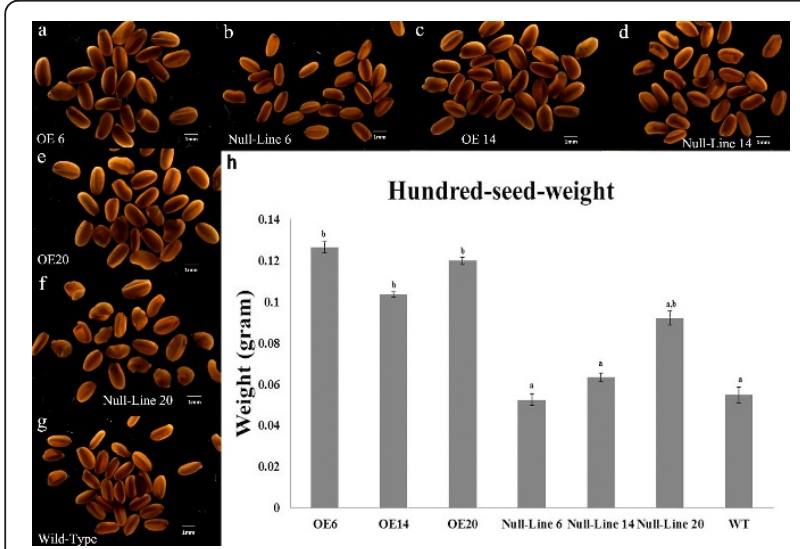

Figure 3 Seed sizes and hundred-seed-weights of T3 homozygous lines. Morphology of seeds harvested from OE6 (a), null-line 6 (b), OE14 (c), null-line 14 (d), OE20 (e), null-line 20 ( $f$ ) and WT (g) plants. All three OE lines produced larger seed size than nulllines and WT plants. (h) The seeds from all three overexpressor lines had higher-hundred-seed weights. Values are means \pm SD $(n=4)$. Different lower case letters indicate significantly different means ( $p$ $<0.05)$. this enzyme is activated in response to carbon starvation and energy-depleting stress conditions [23]. SnRK1 phosphorylates central enzymes involved in primary metabolism (e.g. SPS, nitrate reductase), leading to their inactivation $[3,24]$. We analyzed protein expression levels of SnRK1 and its phosphorylation status by western blotting (Additional file 1). There were no differences in SnRK1 protein expression level or its phosphorylation status among the lines, indicating that higher SPS activity in the OE lines had not resulted from the action of SnRK1 on SPS. Western blotting demonstrated that protein expression levels of other metabolic enzymes, including nitrate reductase (NR), FBPase and FBP aldolase, were unaltered in transgenic plants (Additional file 1). Because anti-AtSPS antibodies from Agrisera (Vännäs, Sweden) did not cross-react with Camelina SPS, we were unable to determine the levels of SPS protein.

\section{Life cycle analysis (LCA) of Camelina-based biodiesel (green diesel) produced from seeds of genetically unaltered and transgenic lines}

SimaPro LCA software is commonly used to construct LCAs of biodiesel produced from different feedstocks. To build a complete life cycle flow tree for the analysis, it is necessary to first build individual life cycle processes in SimaPro. These are then combined into an assembly, and finally into the life cycle as a whole. The functional unit, as well as the point of junction, is one megajoule (MJ) of energy output [25]. Additional file 2 depicts the life cycle flow tree of Camelina-derived fuel from Group 1, namely the group of Camelina seed that were genetically unaltered.

The outputs of genetically modified Camelina seed yields ha ${ }^{-1}$ were assumed to increase by $10 \%$ (Group 2), $20 \%$ (Group 3), 30\% (Group 4), 50\% (Group 5) and 100\% 
Table 2 Higher seed yield from transgenic Camelina lines

\begin{tabular}{llllllll}
\hline Seed Yield (g/plant) & OE6 & OE14 & OE20 & Null-Line 6 & Null-Line14 & Null-Line20 & WT \\
\hline Trial I & $1.73 \pm 0.16^{c}$ & $1.49 \pm 0.20^{c}$ & $1.04 \pm 0.24^{\mathrm{cb}}$ & $0.85 \pm 0.23^{\mathrm{ab}}$ & $0.66 \pm 0.14^{\mathrm{a}}$ & $0.76 \pm 0.24^{\mathrm{a}}$ & $0.89 \pm 0.18^{\mathrm{a}}$ \\
\hline Trial II & $2.22 \pm 0.22^{\mathrm{c}}$ & $2.24 \pm 0.27^{c}$ & $2.09 \pm 0.14^{c}$ & $1.41 \pm 0.07^{\mathrm{ab}}$ & $0.89 \pm 0.25^{\mathrm{b}}$ & $0.74 \pm 0.21^{\mathrm{b}}$ & $1.08 \pm 0.16^{\mathrm{a}}$ \\
\hline
\end{tabular}

Plants were grown in a growth chamber under a $16 \mathrm{~h}$ light $22^{\circ} \mathrm{C} / 8 \mathrm{~h}$ dark $18^{\circ} \mathrm{C}$ temperature/photoperiod regimen and then transferred to a greenhouse after flowering. Values are means \pm SD $(n=4-6)$. Within each row, values marked by different lower case letters are significantly different $(p<0.05)$. Trials I and II were independent experiments carried out in different growing seasons. OE, overexpressed line; WT, wild type.

(Group 6) above yields obtained from farming of genetically unaltered Camelina (Additional file 3). The two impact assessment methods selected for this study were IPCC 2007 Global Warming Potential (GWP) 100a v1.02 and Cumulative Energy Demand (CED). The output for IPCC 2007 GWP is in $\mathrm{CO}_{2}$ equivalents for all of the greenhouse gas (GHG) emissions, including $\mathrm{CO}_{2}, \mathrm{CH}_{4}$, $\mathrm{N}_{2} \mathrm{O}$ and minor contributions from solvents and refrigerants. The second impact assessment method calculates CED for different categories, including non-renewable fossil energy or renewable biomass energy, as MJ-equivalent energy input per MJ energy output. Figure 4 shows GWP, and presents emissions of GHG in terms of $\mathrm{CO}_{2}$ equivalents for the six Camelina cultivation scenarios. The declining GWP from Group 1 through Group 6 demonstrates that emissions of $\mathrm{CO}_{2}$ equivalent per $\mathrm{MJ}$ energy of oil output decreased with increasing seed yields. Table 7 compares CED across the six scenarios. There is a similar slightly decreasing trend from Group 1 to Group 6, indicating a moderate decrease in energy demand with increasing seed yields. As mentioned, seed yields of OE6 and OE14 lines were improved by about $100 \%$ in greenhouse conditions; these two lines would thus fall into Group 6 of the simulation. The LCA results for Group 6 indicate $8.2 \%$ and 2.3\% reductions in GWP and CED, respectively, in comparison with Group 1. Thus, transgenic lines would be more environmentally friendly if yield improvement is reproducible under field conditions.

\section{Discussion}

Sugar metabolism plays important roles in vegetative growth and reproductive development of plants. Sugars affect expression of genes that encode carbon metabolic enzymes $[3,26]$. Developmental processes, such as flowering [27], fruiting [28] and the sink to source transition [29], may be improved by overexpression of SPS. In the present study, overexpression of Arabidopsis AtPAP2 in transgenic Camelina boosted activity of SPS in leaves, similar to the effects in transgenic Arabidopsis [5]. Although SPS activity in leaves was elevated, there was a surprising decrease in leaf sugar contents in the OE lines, contrary to results for transgenic Arabidopsis [5]. The sucrose levels in leaves of 35-d old Camelina were reduced by $20 \%$, suggesting an elevated sucrose export rate in the transgenic lines. The rate of sucrose synthesis under the control of SPS is correlated with the rate of export from leaves [30] and also with the rate of photosynthesis [31]. Higher photosynthetic rates lead to increases in leaf sucrose, while the rate of sucrose export from leaves determines the abundance of sucrose at the source [32]; low leaf sucrose content in overexpressed Camelina lines may have resulted from highly efficient transport of sucrose. High sucrose content in leaves suppresses photosynthesis. Reduced sucrose content in source leaves may alleviate feedback inhibition of photosynthesis and SPS activity caused by high sugar concentrations. Overall, this would enhance carbon fixation and SPS activity. As the major transport carbohydrate in plants, sucrose links carbon assimilation in source tissues to carbon utilization in sink tissues $[18,33]$. Elevated photosynthesis produces more carbon skeletons, while enhanced efficiencies of sucrose synthesis and transport increase sugar supply to sinks, resulting in earlier flowering, faster growth and improved seed yield in transgenic lines.

LCA analysis indicated that improved seed yield of transgenic Camelina sativa lines may prove useful in the production of resource-economical green biodiesel with reduced Cumulative Energy Demand and Global Warming Potential. Compared to petroleum jet fuel, the GHG emission of Camelina-based biofuels was reduced by $68-75 \%$ $(>67 \%)$ at the current yield level from genetically unaltered plants. This could be further improved to $75-80 \%$ by increasing seed yield per unit area. While the transgenic Camelina sativa produced a higher seed yield under

Table 3 Photosynthesis rates of mature leaves (T3)

\begin{tabular}{|c|c|c|c|c|c|c|c|}
\hline Photon flux $\left(\mu \mathrm{mol} \mathrm{m} \mathrm{m}^{-2} \mathrm{~s}^{-1}\right)$ & WT & OE6 & OE14 & OE20 & Null-line 6 & Null-line 14 & Null-line 20 \\
\hline 200 & $7.68 \pm 0.72^{\mathrm{abc}}$ & $9.12 \pm 0.45^{b}$ & $8.34 \pm 1.0^{\mathrm{ab}}$ & $8.09 \pm 0.65^{\mathrm{abc}}$ & $8.27 \pm 0.45^{\mathrm{ab}}$ & $7.16 \pm 1.07^{\mathrm{ac}}$ & $6.56 \pm 0.26^{c}$ \\
\hline 400 & $11.06 \pm 1.34^{\mathrm{a}}$ & $14.73 \pm 0.62^{b}$ & $12.54 \pm 1.41^{\mathrm{ab}}$ & $12.45 \pm 0.90^{\mathrm{ab}}$ & $11.30 \pm 0.62^{\mathrm{a}}$ & $10.29 \pm 1.58^{\mathrm{ac}}$ & $8.82 \pm 0.70^{c}$ \\
\hline 600 & $12.93 \pm 1.42^{\mathrm{ab}}$ & $16.27 \pm 0.67^{b}$ & $15.13 \pm 1.20^{b}$ & $15.12 \pm 0.40^{\mathrm{ab}}$ & $12.93 \pm 0.67^{\mathrm{ab}}$ & $11.81 \pm 1.78^{\mathrm{ac}}$ & $9.67 \pm 0.97^{c}$ \\
\hline 800 & $14.13 \pm 1.55^{\mathrm{a}}$ & $17.89 \pm 0.61^{b}$ & $17.15 \pm 0.96^{b}$ & $16.50 \pm 0.32^{b}$ & $13.96 \pm 0.61^{a}$ & $12.7 \pm 1.70^{\text {ac }}$ & $10.39 \pm 1.04^{c}$ \\
\hline 1000 & $15.02 \pm 1.50^{\mathrm{a}}$ & $19.02 \pm 0.69^{b}$ & $18.35 \pm 1.24^{b}$ & $17.64 \pm 0.52^{b}$ & $14.69 \pm 0.69^{a}$ & $13.51 \pm 1.02^{\text {ac }}$ & $10.91 \pm 0.95^{c}$ \\
\hline
\end{tabular}


Table 4 Stomatal conductance of mature leaves $\left(T_{3}\right)$

\begin{tabular}{|c|c|c|c|c|c|c|c|}
\hline Photon flux $\left(\mu \mathrm{mol} \mathrm{m} \mathrm{m}^{-2} \mathrm{~s}^{-1}\right)$ & WT & OE6 & OE14 & OE20 & Null-line 6 & Null-line 14 & Null-line 20 \\
\hline 200 & $0.16 \pm 0.08^{\mathrm{a}}$ & $0.27 \pm 0.07^{b}$ & $0.17 \pm 0.08^{\mathrm{a}}$ & $0.18 \pm 0.10^{a}$ & $0.16 \pm 0.03^{a}$ & $0.16 \pm 0.13^{\mathrm{a}}$ & $0.13 \pm 0.05^{a}$ \\
\hline 400 & $0.17 \pm 0.07^{\mathrm{a}}$ & $0.28 \pm 0.05^{b}$ & $0.19 \pm 0.07^{a}$ & $0.20 \pm 0.08^{\mathrm{a}}$ & $0.18 \pm 0.04^{a}$ & $0.16 \pm 0.09^{\mathrm{a}}$ & $0.14 \pm 0.04^{a}$ \\
\hline 600 & $0.20 \pm 0.06^{\mathrm{a}}$ & $0.32 \pm 0.04^{b}$ & $0.22 \pm 0.06^{\mathrm{a}}$ & $0.25 \pm 0.07^{a}$ & $0.21 \pm 0.05^{a}$ & $0.18 \pm 0.07^{\mathrm{a}}$ & $0.15 \pm 0.03^{\mathrm{a}}$ \\
\hline 800 & $0.23 \pm 0.05^{a}$ & $0.37 \pm 0.04^{\mathrm{b}}$ & $0.27 \pm 0.05^{\mathrm{ab}}$ & $0.29 \pm 0.07^{\mathrm{ab}}$ & $0.24 \pm 0.06^{a}$ & $0.20 \pm 0.06^{\mathrm{a}}$ & $0.17 \pm 0.03^{a}$ \\
\hline 1000 & $0.27 \pm 0.04^{\mathrm{ab}}$ & $0.41 \pm 0.03^{c}$ & $0.33 \pm 0.04^{b}$ & $0.32 \pm 0.08^{b}$ & $0.27 \pm 0.07^{\mathrm{ab}}$ & $0.22 \pm 0.06^{a}$ & $0.19 \pm 0.03^{a}$ \\
\hline
\end{tabular}

Measurement was carried out on leaves ( $3^{\text {rd }}-4^{\text {th }}$ leaves below the shoot tips) of $35-37-\mathrm{d}$ old Camelina. Photosynthetic rates ( $\left.\mu \mathrm{mol} \mathrm{CO}_{2} / \mathrm{m}^{2} / \mathrm{s}\right)$ and stomatal conductance $\left(\mathrm{H}_{2} \mathrm{O} / \mathrm{m}^{2} / \mathrm{s}\right)$ were measured at different photon fluxes $\left(0-1000 \mu \mathrm{mol} \mathrm{m} \mathrm{m}^{-2} \mathrm{~s}^{-1}\right)$. Within each row, the values marked by different letters $(\mathrm{a}$, b) are significantly different $(p<0.05), \mathrm{n}=3 \sim 5$.

controlled environmental conditions, whether the transgenic lines could perform well under field conditions needs further experiments. Growth density, availability of water, competition of nutrition, pest damages, may adversely affect the growth and yield of the transgenic lines. Nonetheless, with expected future gains in seed yield, Camelina production in USA has the potential to provide three billion liters per year of high quality, environmentally-friendly jet fuel [25]. Commercial use of Camelina-based jet fuel is expected in 2012.

\section{Conclusion}

Overexpression of AtPAP2 promoted Camelina growth through effects on carbon assimilation and distribution. More importantly, improved seed yield could enhance the value of Camelina as a low-input crop for biofuel production and for various industrial and agricultural applications.

\section{Methods}

Plant materials, growth conditions, and vector

Camelina seeds were thrice surface-sterilized with $20 \%$ $(\mathrm{v} / \mathrm{v})$ bleach for $15 \mathrm{~min}$; the seeds were then washed with sterile distilled water thrice before plating onto MS [34] medium supplemented with $2 \%(\mathrm{w} / \mathrm{v})$ sucrose for $5 \mathrm{~d}$. The seedlings were then transferred into $15-\mathrm{cm}$-diameter pots filled with sterilized soil. Camelina plants were then grown in a growth chamber $\left(150 \mu \mathrm{mol}\right.$ photons $\mathrm{m}^{-2} \mathrm{~s}^{-1}$; $75 \% \mathrm{RH})$ under a16 h light $22^{\circ} \mathrm{C} / 8 \mathrm{~h}$ dark $18^{\circ} \mathrm{C}$ temperature/photoperiod regimen and watered every week with distilled water. Collected seeds were dried at $37^{\circ} \mathrm{C}$ in an incubator one week before use. Total RNA was isolated from fresh leaves by using Trizol reagent (Invitrogen, HK.). To generate full-length cDNA for RT-PCR, reverse transcription was performed using M-MLV reverse transcriptase (Promegra, HK). For Camelina transformation, full length AtPAP2 (At1g13900, TAIR Database) cDNA was amplified with Platinum ${ }^{\circledR} P f x$ (Invitrogen, $\mathrm{HK}$ ) and subcloned into the plant transformation vector pBa002 with Xhol and Sacl.

\section{Agrobacterium-mediated transformation}

Six-week old WT Camelina plants that first started flowering in the growth chamber were used for transformation following methodology of Lu et al. [14]. After first transformation, new flowers in inflorescences were used for second and third transformations to improve the transformation ratio. After the third transformation, new inflorescences were cut to reduce background.

\section{Generation of Camelina overexpression lines and null- lines}

Homologous AtPAP2 transgenic lines of Camelina were selected on Basta plates (5 g/l Basta, Riedel-deHaen, Germany, $500 \mathrm{~g} / \mathrm{l}$ carboncillin, 100 seeds/plate); WT Camelina was used as the negative control. Resistant plants were transferred to soil for growth to maturity. Their transgenic status was confirmed by genomic PCR and western blotting analyses using anti-AtPAP2 antibodies. Homozygous $T_{3}$ seeds of the transgenic plants were used for further analyses. When there was 3:1 segregation of $\mathrm{T}_{1}$ transgenic seeds on Basta plates, nulllines were selected by their shorter hypocotyl lengths on MS plates. Identities of the three null-lines were confirmed by genomic PCR.

Seed viability, root and hypocotyl length measurements Camelina seeds were surface sterilized with 20\% (v/v) bleach for 15-20 min, washed with sterile distilled water and then plated on MS medium (50 seeds/plate). The

Table 5 Sugar contents in leaves

\begin{tabular}{|c|c|c|c|c|c|c|c|}
\hline & WT & Null-line 6 & Null-line 14 & Null-line 20 & OE6 & OE14 & OE20 \\
\hline Hexose & $1.78 \pm 0.17^{a}$ & $1.32 \pm 0.20^{b}$ & $1.54 \pm 0.21^{b}$ & $1.39 \pm 0.30^{b}$ & $1.45 \pm 0.15^{b}$ & $1.10 \pm 0.14^{b c}$ & $1.47 \pm 0.48^{b}$ \\
\hline Sucrose & $9.42 \pm 1.36^{\mathrm{a}}$ & $8.55 \pm 0.61^{\mathrm{a}}$ & $8.23 \pm 2.00^{\mathrm{a}}$ & $8.83 \pm 0.80^{a}$ & $7.13 \pm 1.12^{b}$ & $6.00 \pm 0.33^{b}$ & $6.38 \pm 1.42^{b}$ \\
\hline
\end{tabular}

Third and fourth fully mature leaves below the shoot tips were used for measurement. Sugar contents are expressed in $\mu g$ sugar/mg DW (dry weight). Values are means $\pm S D(n=4)$. Within each row, the values marked by different lower case letters are significantly different $(p<0.05)$. OE, overexpressed line; WT, wild type. 
Table 6 Enhanced SPS Enzyme activities in OE lines

\begin{tabular}{|c|c|c|c|c|c|c|c|}
\hline & WT & Null-line 6 & Null-line 14 & Null-line 20 & OE6 & OE14 & OE20 \\
\hline$V_{\max }$ & $13.1 \pm 0.6^{\mathrm{a}}$ & $14.1 \pm 1.6^{\mathrm{a}}$ & $13.2 \pm 1.3^{\mathrm{a}}$ & $12.8 \pm 0.4^{\mathrm{a}}$ & $16.4 \pm 2.2^{b}$ & $21.3 \pm 3.8^{b}$ & $16.0 \pm 1.1^{b}$ \\
\hline$V_{\text {limit }}$ & $2.7 \pm 0.5^{a}$ & $3.4 \pm 0.5^{a}$ & $2.6 \pm 0.3^{a}$ & $3.0 \pm 0.7^{a}$ & $4.8 \pm 1.0^{b}$ & $5.8 \pm 1.4^{b}$ & $5.0 \pm 0.5^{b}$ \\
\hline
\end{tabular}

The third and the fourth fully expanded leaves below the shoot tips were used for SPS enzyme activity analysis after photosynthetic measurements. Enzyme activity is in units of $\mu$ mole sucrose/mg protein/h. Values are means \pm SD $(n=4)$. Within each row, values marked by different lower case letters are significantly different $(p<0.05), \mathrm{n}=4$. OE, overexpressed line; WT, wild type.

experiment was carried out in a growth room $(\sim 100 \mu \mathrm{mol}$ photons $\left./ \mathrm{m}^{2} / \mathrm{s}\right)$ under a $16 \mathrm{~h}$ light $\left(22^{\circ} \mathrm{C}\right) / 8 \mathrm{~h}$ dark $\left(18^{\circ} \mathrm{C}\right)$ temperature/photoperiod regimen. The lengths of roots and hypocotyls were measured $5 \mathrm{~d}$ after germination. Viability tests on Camelina seeds were performed in 10-cm diameter Petri plates each containing $20 \mathrm{ml}$ of MS medium supplemented with $2 \%(\mathrm{w} / \mathrm{v})$ sucrose; results were recorded after 5-6 d.

\section{Extraction of plant genomic DNA and genomic PCR}

Genomic DNA was extracted from young leaves using a CTAB-based method [35]. The $25 \mu \mathrm{l}$ reaction mixture contained $\sim 200 \mathrm{ng}$ of genomic DNA, $0.5 \mu \mathrm{l}$ of each primer (15 mmol/l), $0.5 \mu \mathrm{l}$ of dNTP mix (10 mmol/l each), $5 \mu \mathrm{l}$ of green GoTaq reaction buffer and $0.25 \mu \mathrm{l}$ of GoTaq DNA polymerase (Promega, HK). Cycling began with one cycle at $95^{\circ} \mathrm{C}$ for $2 \mathrm{~min}$, followed by 30 cycles at $95^{\circ} \mathrm{C}$ for $30 \mathrm{~s}, 50^{\circ} \mathrm{C}$ for $30 \mathrm{~s}, 72^{\circ} \mathrm{C}$ for $150 \mathrm{~s}$ and a final extension at $72^{\circ} \mathrm{C}$ for $10 \mathrm{~min}$. PCR products were sequenced using the primers AtPAP2-f (5'-TGCACTCGAGATGATCGTTAATTTCTCTTTC-3') and AtPAP2r (5'-GTACGAGCTCTTATGTCTCCTCGTTCTTG-3'), and analyzed by electrophoresis in $1.0 \%(\mathrm{v} / \mathrm{v})$ agarose gels.

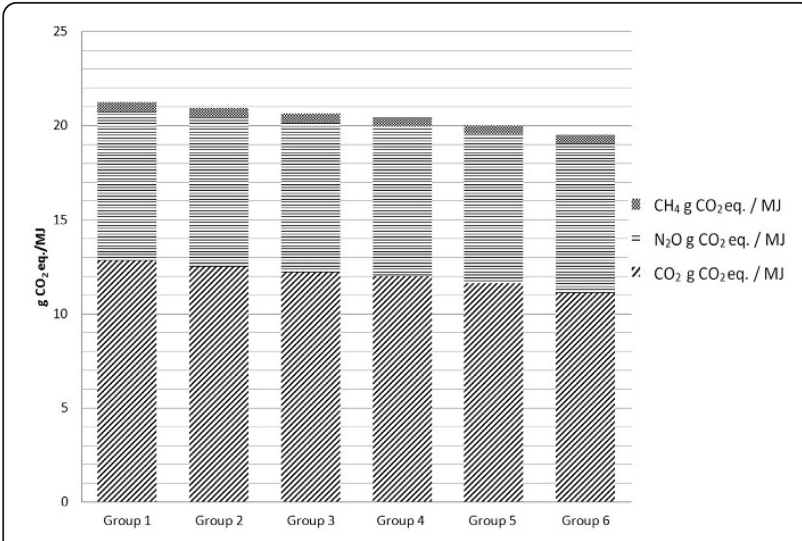

Figure 4 Global warming potential for different Camelina cultivation scenarios. Impact assessments were calculated with IPCC 2007 Global Warming Potential (GWP) 100a v1.02 software; all GHG emissions are presented in terms of $\mathrm{CO}_{2}$ equivalent per $\mathrm{MJ}$ energy in oil output for the six Camelina cultivation scenarios (see Materials and Methods: Fuel Pathways for an explanation of groupings within the cultivation scenarios). $\mathrm{GHG}$ (greenhouse gas) emissions include $\mathrm{CO}_{2}, \mathrm{CH}_{4}, \mathrm{~N}_{2} \mathrm{O}$ and the minor contributions from solvents and refrigerants in $\mathrm{CO}_{2}$ equivalents.

\section{Western blot analysis}

Camelina leaves were finely ground in 1.5-ml Eppendorf tubes each containing $200 \mu \mathrm{l}$ of ice-cooled extraction buffer $(50$ mMTris- $\mathrm{HCl}, \mathrm{pH} 7.4$ containing $150 \mathrm{mMNaCl}$, $1 \mathrm{mM}$ EDTA, and $0.2 \mathrm{mM}$ PMSF) and incubated on ice for $30 \mathrm{~min}$ with occasional mixing. The protein extract was separated by centrifugation at $4{ }^{\circ} \mathrm{C}$ for $30 \mathrm{~min}$ at $10,000 \times g$. The supernatants were transferred to new 1.5$\mathrm{ml}$ Eppendorf tubes and protein concentrations were determined with a Bio-Rad (Hercules, CA, USA) Protein Assay Kit. Proteins separated on 8\% (v/v) SDS-PAGE were transferred to Hybond C-Extra membranes (GE Healthcare, HK) (400 mA, $1 \mathrm{~h}$ ). Membranes were blocked with $5 \%(\mathrm{w} / \mathrm{v})$ non-fat milk in TBST buffer (20 mMTris- $\mathrm{HCl}$, $\mathrm{pH}$ 7.6, $137 \mathrm{mMNaCl}, 0.1 \%$ (v/v) Tween 20) for about $2 \mathrm{~h}$ and probed with specific antiserum for $3 \mathrm{~h}$ at room temperature or overnight at $4^{\circ} \mathrm{C}$. The membrane was rinsed with TBST, and HRP-labeled secondary antibody $(1: 10,000)$ in TBST was added for one more hour. The proteins were visualized with the Enhanced Chemiluminescence method (GE Healthcare, HK).

\section{Measurement of photosynthetic rates and stomatal conductances}

Photosynthetic rates and stomatal conductances were measured using a portable photosynthesis system (LICOR, LI-6400, Nebraska, USA) in the morning (08:3012:30) under a fixed blue-red light-emitting diode (LED) light source. Ten measurements were made on each fully expanded leaf collected from the shoot tips of 35-37-d old plants; at least 3 plants from each line were used for

Table 7 Cumulative Energy Demands

\begin{tabular}{lllllll}
\hline $\begin{array}{l}\text { Impact } \\
\text { Category- }\end{array}$ & $\mathbf{1}$ & $\mathbf{2}$ & $\mathbf{3}$ & $\mathbf{4}$ & $\mathbf{5}$ & $\mathbf{6}$ \\
\hline $\begin{array}{l}\text { Non-renewable, } \\
\text { fossil }\end{array}$ & 0.224 & 0.219 & 0.215 & 0.212 & 0.207 & 0.198 \\
\hline $\begin{array}{l}\text { Renewable, } \\
\text { biomass }\end{array}$ & 1.04 & 1.04 & 1.04 & 1.04 & 1.04 & 1.04 \\
\hline *Others & 0.012 & 0.012 & 0.012 & 0.012 & 0.011 & 0.011 \\
\hline Total & 1.28 & 1.27 & 1.27 & 1.26 & 1.26 & 1.25 \\
\hline
\end{tabular}

*Others include non-renewable biomass and renewable energy sources, such as solar, wind and water, that may be used in the process. The Group 1 column lists the energy demands for cultivation of wild-type Camelina seed; columns under Groups 2, 3, 4, 5 and 6 list demands for cultivating genetically modified plants with various levels of yield improvement $(10 \%, 20 \%, 30 \%$, $50 \%$ and $100 \%$ mass increases per unit area, respectively). Cells contain ratios of $\mathrm{MJ}$ (input)/MJ (output). 
measurements. The leaf area of the standard broadleaf chamber was $6 \mathrm{~cm}^{2}(2 \times 3 \mathrm{~cm})$ and a fixed light source was provided by an array of red and blue LEDs. $P$ vs. $I$ curves were plotted using the instrument's auto-program function. Measurements were taken at light intensities of 200, 400, 600, 800 and $1000 \mu \mathrm{mol}$ photons $/ \mathrm{m}^{2} / \mathrm{s}$.

Photosynthetic rate (A) was calculated as $\mathrm{A}=\mathrm{F}(\mathrm{Cr}-\mathrm{Cs}) /$ $100 \mathrm{~S}-\mathrm{CsE}$, where $\mathrm{A}=$ net assimilation rate $\left(\mu \mathrm{mol} \mathrm{CO} \mathrm{CO}_{2} /\right.$ $\left.\mathrm{m}^{2} / \mathrm{s}^{1}\right), \mathrm{F}=$ molar flow rate of air entering the leaf chamber $(\mu \mathrm{mol} / \mathrm{s}), \mathrm{Cr}=$ mole fraction of $\mathrm{CO}_{2}$ in the reference IRGA (infra-red gas analyzer) ( $\mu \mathrm{mol} \mathrm{CO} 2 / \mathrm{mol}$ air), $\mathrm{Cs}=$ mol fraction of $\mathrm{CO}_{2}$ in the sample IRGA $\left(\mu \mathrm{mol} \mathrm{CO}_{2} / \mathrm{mol}\right.$ air), $\mathrm{S}=$ leaf area $\left(\mathrm{cm}^{2}\right)$, and $\mathrm{E}=$ transpiration rate $(\mathrm{mol}$ $\mathrm{H}_{2} \mathrm{O} / \mathrm{m}^{2} / \mathrm{s}$ ).

Stomatal conductance is the rate at which water evaporates from stomata; it is directly related to the relative size of the stomatal aperture. Conductance is calculated from $\mathrm{gsw}=1 /(1 / \mathrm{gtw}-\mathrm{Kf} / \mathrm{gbw})$, where gsw = stomatal conductance to water vapor $\left(\mathrm{mol} \mathrm{H}_{2} \mathrm{O} / \mathrm{m}^{2} / \mathrm{s}\right)$, gtw $=$ total conductance to water vapor $\left(\mathrm{mol} \mathrm{H}_{2} \mathrm{O} / \mathrm{m}^{2} / \mathrm{s}\right), \mathrm{Kf}=$ stomatal ratio, and gbw $=$ boundary layer conductance to water vapor $\left(\mu \mathrm{mol} \mathrm{H}_{2} \mathrm{O} / \mathrm{m}^{2} / \mathrm{s}\right)$.

\section{HPLC analysis of sugar content}

For measurement of sucrose and hexose of plant tissues, $0.1 \mathrm{~g}$ aliquots of freeze-dried tissue powder were resuspended in $1 \mathrm{ml}$ of $70 \%(\mathrm{v} / \mathrm{v})$ ethanol, incubated at $70^{\circ} \mathrm{C}$ for $90 \mathrm{~min}$ and centrifuged at $13,000 \times g$ for $10 \mathrm{~min}$. After passing through a $0.22 \mathrm{~mm}$ filter, a $10 \mu \mathrm{l}$ sample was injected into a CarboPac PA 1 column $(4 \times 250 \mathrm{~mm})$ connected to a Dionex (Sunnyvale, CA, USA) LC 20 Chromatography system and sugar contents were analyzed by high performance anion exchange chromatography with pulsed amperometric detection [36]. Standard curves were prepared with $0-0.1 \mathrm{mg} / \mathrm{ml}$ sucrose, fructose and glucose solutions in 70\% (v/v) ethanol.

\section{SPS activity assay}

SPS activity was assayed by the anthrone test [22]. Samples were incubated for $20 \mathrm{~min}$ at $25^{\circ} \mathrm{C}$ in $50 \mu \mathrm{l}$ of pre-balanced buffer (50 mM HEPES-KOH pH 7.5, $20 \mathrm{mMKCl}$, and $4 \mathrm{mM} \mathrm{MgCl}_{2}$ ) containing (a) (for $\mathrm{V}_{\max }$ assay) $12 \mathrm{mM}$ UDPG and $10 \mathrm{mM}$ Fru6P (in a 1:4 ratio with glucose-6phosphate (Glc6P), and (b) (for $\mathrm{V}_{\text {limiting }}$ assay) $4 \mathrm{mM}$ UDPG and $2 \mathrm{mM}$ Fru6P (in a 1:4 ratio with Glc6P) and $5 \mathrm{mM} \mathrm{KH}_{2} \mathrm{PO}_{4}$.

\section{Implementation of SimaPro software for life cycle analysis of green diesel from unaltered Camelina and its genetically modified counterparts}

SimaPro was used to construct a LCA (life cycle analysis) of bio-diesel from wild type and genetically modified plants with different seed yields. The general processes for initiating a LCA study in SimaPro include: i. Determining the goal and scope of the specific study, which define the LCA system boundary. ii. Building of the life cycle flow tree, which specifies each stage involved in the life cycle. All environmental inflow and outflow inventory data are collected at this stage to build the life cycle processes; relevant life cycle assembly is then undertaken, followed by final construction of life cycles. Waste scenarios may be added into the life cycle flow tree, if available. iii. Choosing appropriate life cycle impact assessment methodology to calculate prospective results. iv. Interpreting results.

\section{Fuel pathways}

Life cycle analysis was conducted for biofuel derived from unmodified Camelina seeds (Group 1) and for biofuels derived from genetically modified Camelina with enhanced seed yields. We assumed that all input parameters were fixed and that the outputs of genetically modified Camelina seed yield increased by 10\% (Group 2), 20\% (Group 3), 30\% (Group 4), 50\% (Group 5) and 100\% (Group 6) over output from the unmodified Camelina farming process. The whole life cycle was divided into several stages, including Camelina farming, seed oil production, refined oil production and end use oil output, which also set the system boundary defined for the study. The life cycle stages were used to organize data for software calculations.

\section{Functional unit and life cycle inventory}

The function unit in this study was one MJ of energy content in the fuel output. The choice was appropriate since energy content is the fundamental measurement for all environmental and energy flows in the life cycle analysis. The life cycle inventory for every stage came from the public Camelina database for Camelina in Montana, USA and the database in SimaPro. The input data for Camelina farming, seed oil extraction, refined oil production and transportation are shown in Additional file 3, 4 and 5.

As shown in Additional file 3 Group 1 represented the original Camelina seed yield, and Groups 2, 3, 4, 5 and 6 represented the yield increases in genetically modified plants, with seed yields increasing by $10 \%, 20 \%, 30 \%$, $50 \%$ and $100 \%$ per unit area, respectively. The cumulative inputs of potassium $\left(\right.$ as $\left.\mathrm{K}_{2} \mathrm{O}\right)$, thomas meal fertilizer (as $\mathrm{P}_{2} \mathrm{O}_{5}$ ) and urea- $\mathrm{N}$ were fixed for the one-hectare farming input. The quantity of fossil fuel diesel used remained unchanged on a unit area basis but changed with changing Camelina seed output. As for GHG emissions, methane and dinitrogen monoxide emissions per kilogram of seed output remained unchanged. Carbon dioxide emissiona from diesel changed linearly with changing fossil diesel consumption, but at the same time remained fixed per unit area farmland output. 


\section{Growth phenotypes measurement, seed morphology, flowering time, and data analysis}

Duration of time to first bud opening in the primary inflorescence was used as a measure of flowering time in Camelina. Flowering times were recorded in the T1, T2 and T3 generations $(n=4-6)$. Seed morphology of Camelina was observed microscopically. In Tables 1, 2, $3,4,5,6$ statistical differences $(\mathrm{P}<0.05)$ in the same row for each line were based on one-way ANOVA analysis followed by Tukey's Honestly Significant Differences (HSD) test using statistical program SPSS 18.

\section{Additional material}

\section{Additional file 1: Western blot analysis of NR, FBP aldolase,} cFBPase, SnRK1 and its phosphorylation status

Additional file 2: Life cycle flow tree for Group 1 camelina green diesel.

Additional file 3: Cultivation inputs and outputs for camelina farming.

Additional file 4: Processing inputs for camelina seed oil production

Additional file 5: Processing inputs for camelina refined oil production

\begin{abstract}
Abbreviations
AtPAP2: Arabidopsis purple acid phosphatase 2; CED: Cumulative Energy Demand; FBP: Fructose 1,6-bisphosphate; FBPase: Tfructose 1,6bisphosphatase; Fru6P: Frucose-6-phosphate; GHG: Greenhouse gas; GWP: Global Warming Potential; IRGA: Infra-red gas analyzer; LCA: Life cycle analysis; LED: Light-emitting diode; MJ: Megajoule; NR: Nitrate reductase; SPS: Sucrose phosphate synthase; PAP: Purple acid phosphatase; OE: Overexpression; UDPG: UDP-Glucose; WT: Wild-type.
\end{abstract}

\section{Acknowledgements}

This project was supported by the Initiatives for the Clean Energy and Environment (ICEE) of the University of Hong Kong, the General Research Fund (HKU772710M) and the Innovation and Technology Fund (ITS158/09) of the HKSAR, China. We would like to thank Dr. Alice Pilgeram, (Montana State University) for providing WT Camelina sativa variety Suneson. We are thankful to Dr. Lawrence Ramsden for providing the HPLC apparatus. We would like to thank Prof. Samuel Sun (The Chinese University of Hong Kong) for providing the Licor LI-6400XT Portable Photosynthesis System. YZ and FS wish to thank HKU for postgraduate studentships.

\section{Author details}

'School of Biological Sciences, the University of Hong Kong, Pokfulam, Hong Kong, China. ${ }^{2}$ Department of Mechanical Engineering, the University of Hong Kong, Pokfulam, Hong Kong, China. ${ }^{3}$ Department of Applied Biology and Chemical Technology, The Hong Kong Polytechnic University, Hung Hom, Kowloon, China.

\section{Authors' contributions}

YZ designed the study, performed the experiments, analyzed the results and wrote the manuscript. BLL designed the study, analyzed the results and revised the manuscript. LY and DL performed life cycle analysis, participated in manuscript preparation and commentary. FS participated in vector preparation. All authors participated in correction of the manuscript, and approved the final version.

\section{Competing interests}

The authors declare that they have no competing interests.
Received: 11 January 2012 Accepted: 2 April 2012

Published: 2 April 2012

References

1. Sharma-Natu P, Ghildiyal M: Potential targets for improving photosynthesis and crop yield. CurrSci 2005, 88(12):1918-1928.

2. Hammond J, White P: Sucrose transport in the phloem: integrating root responses to phosphorus starvation. J Exp Bot 2008, 59(1):93-109.

3. Smeekens $S$, et al: Sugar signals and molecular networks controlling plant growth. CurrOpin Plant Biol 2010, 13(3):273-278.

4. Baena-Gonzlez E, Sheen J: Convergent energy and stress signaling. Trends Plant Sci 2008, 13(9):474-482.

5. Sun F, et al: A dual-targeted purple acid phosphatase in Arabidopsis thaliana moderates carbon metabolism and its overexpression leads to faster plant growth and higher seed yield. New Phytol 2012, 194(1):206-219.

6. Klabunde $\mathrm{T}$, et al: Mechanism of Fe(III)-Zn(II) purple acid phosphatase based on crystal structures. J MolBiol 1996, 259(4):737-748.

7. Kuang $R$, et al: Molecular and biochemical characterization of AtPAP15, a purple acid phosphatase with phytase activity, in Arabidopsis. Plant Physiol 2009, 151(1):199-209.

8. Lung SC, et al: Phytase activity in tobacco (Nicotianata bacum root exudates is exhibited by a purple acid phosphatase. Phytochemistry 2008, 69(2):365-373.

9. Li WYF, Shao G, Lam HM: Ectopic expression of GmPAP3 alleviates oxidative damage caused by salinity and osmotic stresses. New Phytol 2008, 178(1):80-91.

10. Del Pozo JC, et al: A type 5 acid phosphatase gene from Arabidopsis thaliana is induced by phosphate starvation and by some other types of phosphate mobilising/oxidative stress conditions. Plant J 1999, 19(5):579-589.

11. Kaida $R$, et al: Potential role for purple acid phosphatase in the dephosphorylation of wall proteins in tobacco cells. Plant Physiol 2010, 153(2):603-610.

12. Kaida $\mathrm{R}$, et al: Isolation and characterization of four cell wall purple acid phosphatase genes from tobacco cells. BiochimicaetBiophysicaActa (BBA)Gene Structure and Expression 2003, 1625(2):134-140.

13. Zubr J: Oil-seed crop: Camelina sativa. Ind Crop Prod 1997, 6(2):113-119.

14. Lu C, Kang J: Generation of transgenic plants of a potential oilseed crop Camelina sativa by Agrobacterium-mediate transformation. Plant Cell Rep 2008, 27(2):273-278.

15. Vollmann J, et al: Improvement of Camelina sativa an underexploited oilseed. Progress in new crops. ASHS Press, Alexandria, VA 1996, 1:357-362.

16. Gebauer SK, et al: n-3 Fatty acid dietary recommendations and food sources to achieve essentiality and cardiovascular benefits. Am J ClinNutr 2006, 83(6):S1526-S1535.

17. Ainsworth $E A$, Rogers $A$ : The response of photosynthesis and stomatal conductance to rising $\left[\mathrm{CO}_{2}\right]$ : mechanisms and environmental interactions. Plant Cell Environ 2007, 30(3):258-270.

18. Paul M, Foyer C: Sink regulation of photosynthesis. J Exp Bot 2001 52(360):1383-1400.

19. Meyer $\mathrm{R}$, et al: The metabolic signature related to high plant growth rate in Arabidopsis thaliana. ProcNat/AcadSci 2007, 104(11):4759-4764.

20. Stitt M, Quick WP: Photosynthetic carbon partitioning: its regulation and possibilities for manipulation. Physiol Plant 1989, 77(4):633-641.

21. Signora $L$, et al: Over-expression of sucrose phosphate synthase in Ababidopsis thaliana results in increased foliar sucrose/starch ratios and favours decreased foliar carbohydrate accumulation in plants after prolonged growth with $\mathrm{CO}_{2}$ enrichment. J Exp Bot 1998, 49(321):669-680.

22. Baxter $\mathrm{C}$, et al: Elevated sucrose-phosphate synthase activity in transgenic tobacco sustains photosynthesis in older leaves and alters development. J Exp Bot 2003, 54(389):1813-1820.

23. Polge C, Thomas M: SNF1/AMPK/SnRK1 kinases, global regulators at the heart of energy control? Trends Plant Sci 2007, 12(1):20-28

24. Halford N, Hey S: Snf1-related protein kinases (SnRKs) act within an intricate network that links metabolic and stress signalling in plant. Biochem J 2009, 419:247-259.

25. Shonnard DR, Williams L, Kalnes TN: Camelina-derived jet fuel and diesel: Sustainable advanced biofuels. Environmental Progress \& Sustainable Energy 2010, 29(3):382-392. 
26. Mahmoud SS, Croteau RB: Strategies for transgenic manipulation of monoterpene biosynthesis in plants. Trends Plant Sci 2002, 7(8):366-373.

27. Micallef $\mathrm{V}$, et al: Altered photosynthesis, flowering, and fruiting in transgenic tomato plants that have an increased capacity for sucrose synthesis. Planta 1995, 196(2):327-334.

28. Nguyen-Quoc B, et al: Overexpression of sucrose phosphate synthase increases sucrose unloading in transformed tomato fruit. J Exp Bot 1999, 50(335):785-791.

29. Cheng WH, Im KH, Chourey PS: Sucrose phosphate synthase expression at the cell and tissue level is coordinated with sucrose sink-to-source transitions in maize leaf. Plant Physiol 1996, 111(4):1021-1029.

30. Chincinska IA, et al: Sucrose transporter StSUT4 from potato affects flowering, tuberization, and shade avoidance response. Plant Physiol 2008, 146(2):515-528

31. Battistelli A, Adcock M, Leegood R: The relationship between the activation state of sucrose-phosphate synthase and the rate of $\mathrm{CO}_{2}$ assimilation in spinach leaves. Planta 1991, 183(4):620-622.

32. Ho L, Thornley J: Energy requirements for assimilate translocation from mature tomato leaves. Ann Bot 1978, 42(2):481-483.

33. Farrar J: Sinks-integral parts of a whole plant. J Exp Bot 1996, 47(Sepecial):1273-1279.

34. Murashige T, Skoog F: A revised medium for rapid growth and bio assays with tobacco tissue cultures. Physiol Plant 1962, 15(3):473-497.

35. Lukowitz W, Gillmor CS, Scheible WR: Positional cloning in Arabidopsis. Why it feels good to have a genome initiative working for you. Plant Physiol 2000, 123(3):795-806.

36. Baroja-Fernndez E, et al: Sucrossynthase catalyzes the de novo production of ADPglucose linked to starch biosynthesis in heterotrophic tissues of plants. Plant Cell Physiol 2003, 44(5):500-509.

doi:10.1186/1754-6834-5-19

Cite this article as: Zhang et al: Over-expression of AtPAP2 in Camelina sativa leads to faster plant growth and higher seed yield. Biotechnology for Biofuels 2012 5:19.

\section{Submit your next manuscript to BioMed Central and take full advantage of:}

- Convenient online submission

- Thorough peer review

- No space constraints or color figure charges

- Immediate publication on acceptance

- Inclusion in PubMed, CAS, Scopus and Google Scholar

- Research which is freely available for redistribution

Submit your manuscript at www.biomedcentral.com/submit
Biomed Central 